\title{
What Are the Unmet Information Needs of Cancer Patients? A Qualitative Study
}

\author{
Fatima Yatim $\mathrm{PhD}^{1}$, Paula Cristofalo $\mathrm{PhD}^{1}$ \& Etienne Minvielle $\mathrm{MD}, \mathrm{PhD}^{1,2}$ \\ ${ }^{1}$ EA 7348 Management des Organisations en santé (MOS), EHESP School of Public Health, Rennes-Paris, France \\ ${ }^{2}$ Gustave Roussy Cancer Center Villejuif, France \\ Correspondence: Fatima Yatim EHESP School of Public Health, 20, rue George Sand -93210 La Plaine \\ Saint-Denis, France. Tel: 33-646-448-120. E-mail: Fatima.YATIM-DAUMAS@ehesp.fr
}

\author{
Received: August 23, 2017 Accepted: October 9, 2017 Online Published: October 31, 2017 \\ doi:10.5539/gjhs.v9n12p114 \\ URL: https://doi.org/10.5539/gjhs.v9n12p114
}

\begin{abstract}
Objective: Identify the unmet information needs of cancer patients and understand the causes of patients' dissatisfaction

Methods: A qualitative method using interviews with cancer patients attending a Meeting and Information Area (ERI) at Gustave Roussy cancer center (France), and focus groups with the ERI professionals. The data were analysed using vertical and horizontal open coding.

Results: Firstly, the needs for medical information are important, but there are other types of information that patients need (e.g. organizational information). Secondly, patients' dissatisfaction is not linked only to the lack of medical information; it also reflects other needs, which are not taken into account (e.g. accompanying information to make it understandable and useful). Thirdly, the relationships established over time between patients and professionals make possible the emergence of latent needs (ranging from basic information needs to requests for psychological support).
\end{abstract}

Conclusion: Information must be considered in an integrated and holistic approach to facilitate patients' navigation and improve their health literacy.

Practice Implications: The training of healthcare professionals is crucial, but this is not enough. The introduction of other, non-carers professionals is necessary to address a broad range of patients' needs in a more effective and cost-efficient way.

Keywords: cancer patients, unmet information needs, qualitative research, health literacy

\section{Introduction}

Providing patients with the information they need is crucial. It has been demonstrated that, compared to informed patients, uninformed patients are less likely to use preventive services and manage their own cares (Vernon, Trujillo, Rosenbaum, \& DeBuono, 2007). Many studies have showed that patients need to know about their disease, diagnosis, prognosis and treatment (Browall, Carlsson, \& Horvath, 2004; Morrison, Henderson, Zinovieff et al., 2012; Tsuchiya \& Horn, 2009). The most frequently expressed information needs were related to cancer treatment, followed by information related to specific cancer type (Rutten, Arora, Bakos, Aziz, \& Rowland, 2005).

The amount and type of information needed depend on cancer trajectory and on patients' demographics and clinical characteristics (Ankem, 2006). It has been shown that older cancer patients tend to seek less information than younger patients (Ankem, 2006; Cox, Jenkins, Catt, Langridge, \& Fallowfield, 2006; Galarce et al., 2011). Also, female cancer patients usually seek more information than males (Jenkins, Fallowfield, \& Saul, 2001; Matsuyama, Kuhn, Molisani, \& Wilson-Genderson, 2012), and single patients seek less information than married patients (Galarce et al., 2011; Matsuyama et al., 2012). However, there is no consensus about the educational level. Indeed, some studies reported that patients with a low educational level seek more information than those with a high educational level (Matsuyama et al., 2012; Matsuyama et al., 2011), but other studies reported contrary results (Galarce et al., 2011). Lastly, five sources of information were reported: healthcare providers (physicians (43\%) and nurses (28\%) were most frequently reported as the source of information), followed by printed materials, media, organizational and scientific resources (Rutten et al., 2005). 
Furthermore, a study conducted by Morrison et al. (2012) to explore the unmet needs of cancer patients showed that informational needs about cancer, its treatment and side effects, topped the list of unmet needs. Thus, there is a need for additional studies to explain the reasons for these unmet needs and how patients meet them (Al Qadire, 2014).

The purpose of this paper is to identify the unmet information needs of cancer patients and understand the causes of patients' possible dissatisfaction.

\section{Methods}

Research was based on a qualitative methodology using two techniques: semi-structured interviews with cancer patients, under treatment or in remission, attending a Meeting and Information Area (Espace de Rencontres et d'Information-ERI) at Gustave Roussy cancer center (Villejuif, France), and focus groups with the two professionals who are in charge of the ERI.

\subsection{Setting and Participants}

The ERI is dedicated to patient information through the provision of information documents validated by practitioners, the organization of information meetings between patients and practitioners, and the reception of patients on site. It was created in 2001 by Gustave Roussy cancer center in partnership with the French National Cancer League.

The two ERI professionals helped recruiting patients for the study. Patients were identified in a non-consecutive manner to provide a representative sample with regards to age, gender, and specific diagnosis. The recruiter then approached prospective participants, explaining the study and providing them with printed information realized by researchers. Researchers subsequently contacted those who accepted to partake in the study.

Nineteen interviews with patients and two focus groups with the two ERI professionals proved sufficient to achieve data saturation (Strauss \& Corbin, 2014).

\subsection{Data Collection}

Interviews lasted on average one hour. They were conducted over two periods of two months, from July to August and from November to December 2015. They were formatted following an interview guide that was structured around three main themes:

- The main reasons for coming to the ERI (e.g. specific need, first visit, pace of visits);

- The unmet information needs and unmet needs in general;

- The causes of their dissatisfaction as cancer patients about information received.

Additional time was allowed for more open exploration of unanticipated issues raised by the participants during the interview.

The focus groups lasted two hours each. They were conducted over the same period and were structured around the same themes, except that researchers added questions about the professional training, skills and motivations of the interviewees. The first focus group was conducted before the interviews with the patients were done and the second was conducted after the interviews in order to discuss the results of patients' interviews with the ERI professionals.

All interviews and focus groups were digitally audio-recorded for verbatim transcription. Demographic patients data including age, sex, occupation and diagnosis were collected.

\subsection{Data Analysis}

Verbatim transcripts of all interviews and focus groups were prepared by a professional transcriptionist, checked for accuracy against the sound files by the interviewers, and corrected where necessary.

Data were analysed using open coding by two researchers in an inductive posture (Strauss \& Corbin, 2014). Firstly, vertical coding was used to identify the anticipated and emergent themes. Vertical coding also made it possible to define the meaning of the items identified within each of the three anticipated themes. Secondly, horizontal coding was used to combine and compare the meaning of each item. The themes and items generated independently by each researcher were then compared and discussed with the principal investigator until a consensus was reached.

\subsection{Research Ethics}

Participation was entirely voluntary and informed consent was obtained systematically. During the interviews, all patients were encouraged to speak freely and they were assured that their information would be kept confidential 
and that the data would be processed anonymously.

\section{Results}

\subsection{Patient Profiles}

Thirty-five patients were approached, twenty-five expressed interest in participating, and nineteen were eventually interviewed; others could not be interviewed for logistic reasons. Patients interviewed show no typical information profile; for example, some patients often consult internet (8/19) but others consult only occasionally (7/19), and none of them wish to be informed of all aspects of their disease. Their visit to the $E R I$ can be punctual or regular (among them, 6 over 19 were identified as regular patients). All patients met went to the ERI for the first time during their hospitalization. Details on patient demographics are shown in Table 1.

Table 1. Patient demographics

\begin{tabular}{lll}
\hline \multirow{2}{*}{ Age (years) } & Range (30/70) & \\
\hline Sex & $(15$ of 19 were 40-60 years old $)$ & 12 \\
Education level & Female & 7 \\
& Male & 13 \\
Diagnostic & Higher level & 6 \\
& Primary and secondary levels & 5 \\
& Breast cancer & 1 \\
& Bone cancer & 3 \\
& Rectal cancer & 1 \\
& Skin cancer & 2 \\
& Gastric cancer & 2 \\
& Colon cancer & 2 \\
& Brain cancer & 1 \\
& Testicular cancer & 2 \\
& Uterine cancer & 2 \\
\hline
\end{tabular}

\subsection{Thematic Analysis}

\subsubsection{Patient Information Needs}

All patients interviewed said they visited the $E R I$ for the first time because they were looking for information or documentation on treatments. However, there are other types of information that patients sought. Research led to identify three types of non-medical information:

a) Information on the care pathway, on the hospital and on the health care system in general (e.g. administrative rules, organization of departments);

b) Information on supportive care (e.g. services, activities) and how to contact professionals inside and outside the hospital (e.g. dietician, psychologist);

c) Information on living with cancer and its consequences on daily activities.

In addition, some visits are not motivated by information needs, whether medical or non-medical, but related to requests for advice or help regarding difficulties experienced during the care pathway. It is for instance the case of this patient:

"I live in the South of France. When I consulted the doctor at the hospital, he prescribed a scanner quickly. After the analysis, the doctor I already knew asked that I see urgently someone in a specialized hospital in Paris. He said he would call himself to get me an appointment. He got it for 3 days later. So, I caught a plane, I was assured everything would be taken care of, by Social security, yet, my trips have never been reimbursed. The flight, the hotel for my husband... As a case of urgency, we asked for a loan so that we could handle the situation. But I wasn't sure of what I could reclaim. It is one of the first questions I asked at the ERI." (Woman, 57 years old, brain cancer 
patient, sales assistant).

Those difficulties may have been encountered both inside the hospital (e.g. conflicts or communication problems between patients and professionals) and outside the hospital (e.g. financial issues, privacy).

Besides, regardless of the type of cancer, patients interviewed said that their needs vary over time. Firstly, needs vary in their nature: information needs on the disease and treatments at the beginning of the care pathway versus listening needs during and after the phases of active treatment.

"The surgeon had explained to me very well what the operation was all about [reconstructive surgery following an ablation] but I needed to know more, to see photos, to take advice from people who had gone through it. I needed it because I had previously experienced a reconstructive surgery that didn't work, I needed reassuring, I had to be sure that I was not doing all this for nothing" (Woman, 60 years old, breast cancer patient, retired)

Secondly, needs vary in intensity, which does not systematically depend on therapy stage (e.g. diagnostic, treatment, after cancer). The intensity of the needs depends on the social and personal situation of each patient (e.g. socially isolated patients):

"I'm shy, I feel like I need the doctor encouraging me so that I can speak out and share my doubts with him [...]. At the beginning, I didn't receive enough explanations on chemotherapy. When the doctor gave me pills, I didn't even know it was chemo. I went to get them at the pharmacy, I read the instructions but I didn't understand. I was still spaced out because of the diagnosis. I was alone and I needed a person to speak to, you know, when you're not well, the slightest thing stresses you out. I had gone to the ERI once, so I went back. I understood that these drugs were the chemo (oral chemotherapy), I don't know what was happening, I was expecting something else. At the ERI I found additional information." (Woman, 63 years old, rectum cancer, administrative employee)

Thus, in addition to information and documentation needs, in a majority of cases, additional needs emerged during visits:

"I came here at the beginning because I had no Wifi in my house. I just wanted to surf the Net to get some information about side effects. I discussed this with $X$ and she guided me to get relevant information, on the most serious websites, but she saw I was still curious, even anxious. She recommended me several books, not too many because I would have drowned. I learned lots of things, especially on treatments that could help me, but also on how to manage my appointments and ask the relevant questions" (Man, 53 years old, testicular cancer, employer)

Professionals say that lots of patients come at the beginning to get information about side effects or guidance in the hospital, and eventually end up looking mostly for nutritional information and/or supportive care outside of the hospital.

\subsubsection{Unmet and Latent Needs}

Medical information needs are the main motivation for visiting the $E R I$ at the first time. However, these needs are often combined with other types of needs depending on each case and depending on the relationship of trust established over time with ERI professionals. We distinguished four levels of patient needs as shown in Figure 1:
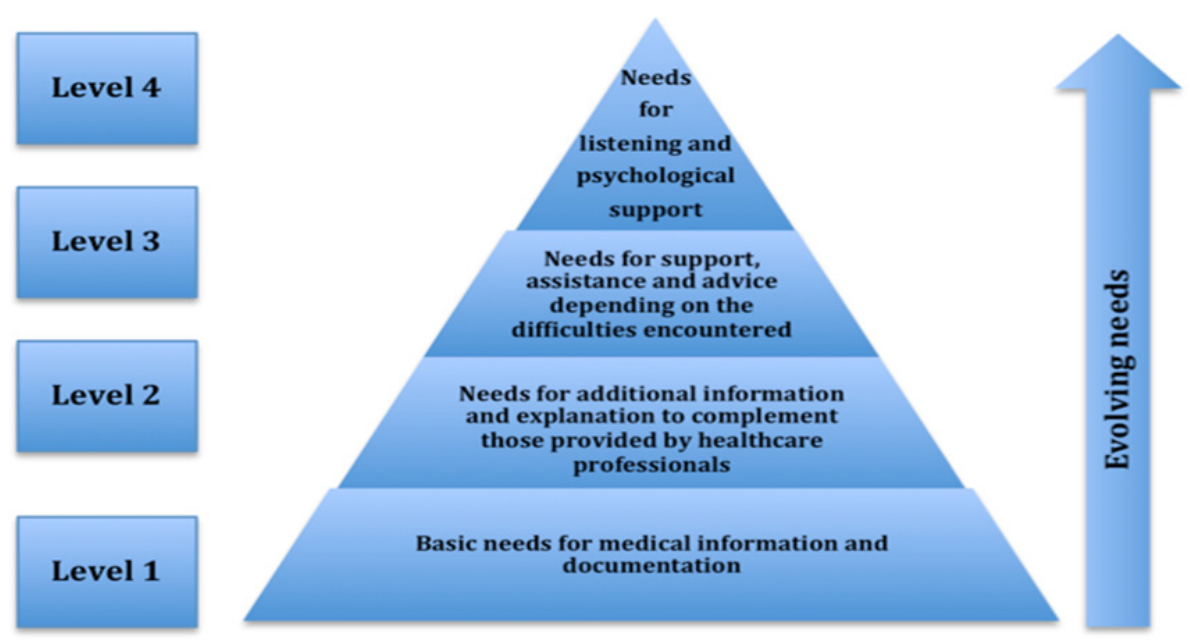

Figure 1. Levels of patients' needs 
Therefore, although the first visits were systematically motivated by a search for medical information and documentation, patients also underlined a number of latent needs. Patients stressed that apart from this first motivation, they were seeking listening and dialogue and were wishing more support for their specific needs:

"I had already undergone surgery several times, therefore I wasn't so afraid about the operation. I was very cool about it, however, when I heard 'cancer' and many other barbaric words like 'chemo', 'care pathway' and all those things, I was far less relaxed... I set foot here once and then I came back on a regular basis, as if it were part of my treatment. Each time I had a visit, each time I had an important appointment, I would go first to the ERI. Sometimes just to say hello, to speak, sometimes with more specific interrogations... I speak easily and therefore, every time it would end with X saying to me "Come on Ms Y, now it's time for your chemo" or any other thing... I needed this moment to arrive at the session quieter, more confident, or even sometimes just to go!" (Woman, 47 years old, Breast cancer, engineer)

One of the ERI professionals also mentions it: "For patients sometimes it's like a ritual, we're like a comforter, coming by helps them to better accept the treatment, the different sessions, and even the observance of medical prescriptions" (Woman, ERI professional). Although essential, human relations and conviviality are not the only features patients mention about the ERI. Other patients also stress the fact that it is a place where they can find "reliable advice", professionals make inquiries when they don't have an answer straightaway.

The $E R I$ is therefore identified as a "neutral area", a non-medical space outside the care pathway, where patients can express themselves freely. A place where patients and relatives may go without an appointment and as many times as they wish. The ERI professionals are here to support patients in their care pathway but do not have access to their medical file. These professionals translate in "neutral" or "simple" terms of information that is not medically customised although adapted to individual histories. As one of the ERI professionals puts it: "It was important for us not to wear white coats, for we didn't want to be mistaken with health care professionals. ...". They help patients to translate information, to understand their treatment and the health system, and to become more active in it" (Woman, ERI professional).

\subsubsection{The Causes of Dissatisfaction}

According to the patients interviewed, dissatisfaction about the information provided is explained mainly by the lack of availability of health professionals in the hospital. For the case of the oncologists in particular, the duration of medical consultations is deemed insufficient, and does not allow patients to receive and understand all the medical information they need. In addition, the ERI also provides other types of information that patients may require such as organizational information. In fact, the second reason identified by interviewees to explain the perceived inadequacy of information and their dissatisfaction is related to the lack of knowledge about the hospital organization and about the functioning of the healthcare system in general: the role of the various professionals; the care pathway organization; how departments work within the hospital; the coordination between professionals in the hospital and primary care providers, etc.:

"I couldn't understand if the doctor would set up the appointment, if I had to wait for the anaesthetist, I had written it down but I couldn't make sense of it. I was afraid of getting back to him and be like a pain in the arse. But I was just as much as afraid to wait passively and miss the date of the operation. Was it my responsibility to make the appointment? I was always wondering whether my questions were relevant or stupid. For instance, what kind of clothes should I bring with me at the hospital!" (Man, 65 years old, gastric cancer, retired)

This is particularly true during the transitions between the different phases of active treatment (surgery, chemotherapy, radiation). Indeed, patients who have, or have had several treatments or several cares, said that they were "lost" between the different departments:

"you see the physician, you see the oncologist, you see the surgeon, you see the radiologist, there are the nurses that attend to you the day of the operation, you see the ones that take care of you, but it doesn't look like it's really coordinated [...] You're quite lost, you don't know who to speak to, so for me the ERI allowed me to connect the dots between all these people, to better understand, and it appeased me. X has always kept a neutral position, but she always enlightened me" (Woman, 52 years old, Breast cancer, journalist)

But this is also true for handover cases between the hospital and the primary care providers, more particularly when there is no regular communication between the hospital and the family doctor to assure follow-up care at home (e.g. sharing hospitalization or consultation records, sharing examination and analysis results).

\section{Discussion and Limitations}

Patients who visit the ERI are mostly women (12/19). This finding confirms the results of many studies on the 
demographics of patients who are most in search of information (Jenkins et al., 2001; Matsuyama et al., 2012). Patients are of a high level of education (Galarce et al., 2011). When patients visited the ERI for the first time, their first motivation was to obtain information about the disease, treatments and side effects depending on the type of cancer (Vernon et al., 2007; Browall et al., 2004; Morrison et al., 2012; Tsuchiya et al., 2009; Rutten et al., 2005). All patients interviewed visited the ERI for the first time during their hospitalization, at the beginning of their treatment. In addition, information needs vary over time and they are more important in the diagnostic phase and in the first periods of treatment as all studies show (Rutten et al., 2005; Matsuyama et al., 2012).

While confirming previous studies, and despite a small sample, our work provides additional qualitative results on unmet needs and reasons for the dissatisfaction of patients regarding the information they receive. This point is not sufficiently mentioned in the literature (Morrison et al., 2012; Al Qadire, 2014). Our study shows that the needs for medical information are important, but that there are other types of information that are needed by patients throughout their care pathway (e.g. about the care pathway organization; about hospital organization, and about the health system in general; on how to contact supportive care providers; on the day-to-day living with cancer and after cancer). The lack of understanding of the organizational aspects of the care pathway (for example, how departments work and how they coordinate between themselves; who to contact according to each need), creates the feeling that the information received is insufficient. Therefore, needs do not only relate to medical information, they also include health and organizational information necessary for patient navigation.

Our study also shows that satisfaction about the information provided depends on the quality of the relationship between patients and professionals who give the information (Morrison et al., 2012; Llewellyn, McGurk, \& Weinman, 2006). The perceived insufficiency of information also seems to refer to a need for additional medical explanations and a need of translating the medical terms (Kessels, 2003). Indeed, patients said that there are many sources of information (documentation sent by the hospital or website), but that is not enough. Therefore, patient needs include not only access to information, but also the ways of communicating and accompanying information to make it understandable (Vernon et al., 2007; Koh, Brach, Harris, \& Parchman, 2013; Hibbard, Greenlick, Jimison, Capizzi, \& Kunkel, 2001; Berkman, Sheridan, Donahue, et al., 2011). For example, the information provided during consultations with the oncologist does not appear to be sufficient to meet patient needs (Nielsen-Bohlman, Panzer, \& Kindig, 2004). Difficulties in understanding, memory problems, anxiety, and patient's vulnerability in relation to the doctor are further factors, which impede better communication between patients and doctors (Kessels, 2003).

In addition to facilitating access to information, the ERI therefore also plays an important organizational role in responding to many "unsatisfied subsidiary needs". The relationships established over time between patients and ERI professionals make possible the emergence of these needs and their legitimation. ERI professionals help patients to better manage their care pathway by providing the organizational information and health information needed. They complement services provided within the hospital and strengthen the hospital organization. In doing so, they contribute to the development of "health-literate organizations", a concept employed by the Institute of Medicine in a discussion paper to designate organizations that support people as they navigate, understand, and use information and services to take care of their health (Brach, Keller, Hernandez, et al., 2012).

The study has certain limitations in addition to the small size of the sample. First, the study was conducted in only one cancer center; the skills, personal qualities and the role of professionals working in services dedicated to information may depend on each cancer center. Second, ERI professionals recruited patients and the participation was entirely voluntary; hence, the participants may not entirely reflect the opinions of all patients treated at Gustave Roussy.

\section{Conclusion and Practice Implications}

Information must be considered in an integrated and holistic approach, which includes both medical and organizational aspects. This is necessary for patients to improve their understanding and facilitate their navigation. Therefore, the development of services such as those provided by the ERI within cancer centers must be used to contribute to the improvement of "health literacy" and help patients to be more involved in their treatment.

Healthcare providers should lay emphasis on the medical information, but they also should take into account the importance of accompanying patients to make this information understandable and useful. Therefore, the training of healthcare professionals is crucial, but this is not enough. The introduction of other professionals, which are non-carers, is necessary to address a broad range of patients' needs more effectively and more cost-efficiently.

\section{Acknowledgements}

We thank all patients, ERI professionals and Marilène Lacaze, Marie Ferrua, Aude Fourcade, for the support that 
they provided to carry out this study.

\section{Competing Interests Statement}

The authors declare that there are no competing or potential conflicts of interest.

\section{References}

Al Qadire, M. (2014). Jordanian cancer patients' information needs and information-seeking behavior: A descriptive study. European Journal of Oncology Nursing, 18, 46-51. https://doi.org/10.1016/j.ejon.2013.09.007

Ankem, K. (2006). Factors influencing information needs among cancer patients: A meta-analysis. Library \& Information Science Research, 28, 7-23. https://doi.org/10.1016/j.lisr.2005.11.003

Berkman, N. D., Sheridan, S. L., Donahue, K. E., Halpern, D. J., Viera, A., Crotty, K., ... \& Tant, E. (2011). Health literacy interventions and outcomes: an updated systematic review. Evidence report/technology assessment, 199, 1-941. Retrieved from http://www.ncbi.nlm.nih .gov/books/n/erta199/pdf/

Brach, C., Keller, D., Hernandez, L. M., Baur, C., Dreyer, B., Schyve, P., ... \& Schillinger, D. (2012). Ten attributes of health literate health care organizations (pp. 1-26). Washington, DC: Institute of Medicine of the National Academies. Retrieved from http://iom.edu/ /media/Files/Perspectives-Files/2012/Discussion-Papers/BPH Ten_HLit_Attributes.pdf

Browall, M., Carlsson, M., \& Horvath, G. (2004). Information needs of women with recently diagnosed ovarian cancer-a longitudinal study. European Journal of Oncology Nursing, 8(3), 200-207. https://doi.org/10.1016/j.ejon.2003.12.007

Cox, A., Jenkins, V., Catt, S., Langridge, C., \& Fallowfield, L. (2006). Information needs and experiences: an audit of UK cancer patients. European Journal of Oncology Nursing, 10(4), 263-272. https://doi.org/10.1016/j.ejon.2005.10.007

Galarce, E. M., Ramanadhan, S., Weeks, J., Schneider, E. C., Gray, S. W., \& Viswanath, K. (2011). Class, race, ethnicity and information needs in post-treatment cancer patients. Patient education and counseling, 85(3), 432-439. https://doi.org/10.1016/j.pec.2011.01.030

Hibbard, J. H., Greenlick, M., Jimison, H., Capizzi, J., \& Kunkel, L. (2001). The impact of a community-wide self-care information project on self-care and medical care utilization. Evaluation \& the health professions, 24(4), 404-423. https://doi.org/10.1177/01632780122034984

Jenkins, V., Fallowfield, L., \& Saul, J. (2001). Information needs of patients with cancer: results from a large study in UK cancer centres. British journal of cancer, 84(1), 48-51. https://doi.org/10.1054/bjoc.2000.1573

Kessels, R. P. (2003). Patients' memory for medical information. Journal of the Royal Society of Medicine, 96(5), 219-222. https://doi.org/10.1258/jrsm.96.5.219

Koh, H. K., Brach, C., Harris, L. M., \& Parchman, M. L. (2013). A proposed 'health literate care model'would constitute a systems approach to improving patients' engagement in care. Health Affairs, 32(2), 357-367. https://doi.org/10.1377/hlthaff.2012.1205

Llewellyn, C. D., McGurk, M., \& Weinman, J. (2006). How satisfied are head and neck cancer (HNC) patients with the information they receive pre-treatment? Results from the satisfaction with cancer information profile (SCIP). Oral oncology, 42(7), 726-734. https://doi.org/10.1016/j.oraloncology.2005.11.013

Matsuyama, R. K., Kuhn, L. A., Molisani, A., \& Wilson-Genderson, M. C. (2013). Cancer patients' information needs the first nine months after diagnosis. Patient education and counseling, 90(1), 96-102. https://doi.org/10.1016/j.pec.2012.09.009

Matsuyama, R. K., Wilson-Genderson, M., Kuhn, L., Moghanaki, D., Vachhani, H., \& Paasche-Orlow, M. (2011). Education level, not health literacy, associated with information needs for patients with cancer. Patient education and counseling, 85(3), e229-e236. https://doi.org/10.1016/j.pec.2011.03.022

Morrison, V., Henderson, B. J., Zinovieff, F., Davies, G., Cartmell, R., Hall, A., \& Gollins, S. (2012). Common, important, and unmet needs of cancer outpatients. European Journal of Oncology Nursing, 16(2), 115-123. https://doi.org/10.1016/j.ejon.2011.04.004

Nielsen-Bohlman, L., Panzer, A. M., \& Kindig, D. A. (2004). Health literacy: a prescription to end confusion. Washington (DC): National Academies Press. 
Rutten, L. J. F., Arora, N. K., Bakos, A. D., Aziz, N., \& Rowland, J. (2005). Information needs and sources of information among cancer patients: A systematic review of research (1980-2003). Patient education and counseling, 57(3), 250-261. https://doi.org/10.1016/j.pec.2004.06.006

Strauss, A., \& Corbin, J. (2014). Basics of qualitative research: techniques and procedures for developing grounded theory. Sage Publications.

Tsuchiya, M., \& Horn, S. A. (2009). An exploration of unmet information needs among breast cancer patients in Japan: a qualitative study. European Journal of Cancer Care, 18, 149-155. https://doi.org/10.1111/j.1365-2354.2008.00936.x

Vernon, J. A., Trujillo, A., Rosenbaum, S., \& DeBuono, B. (2007). Low health literacy: implications for national health policy [Internet]. Washington (DC): George Washington University. Retrieved from http://sphhs.gwu.edu/departments/healthpolicy/CHPR/downloads/LowHealthLiteracyReport10_4_07.pdf

\section{Copyrights}

Copyright for this article is retained by the author(s), with first publication rights granted to the journal.

This is an open-access article distributed under the terms and conditions of the Creative Commons Attribution license (http://creativecommons.org/licenses/by/4.0/). 